\title{
A New Method to Calculate the Recoverable Reserves and Recovery Ratio of Shale Gas Reservoir
}

\author{
Maolin Zhang, Yizhong Zhang*, Long Yang, Haiyan Mei, Pengxiang Shen, Jingnan Ge
}

Electronics \& Information College of Yangtze University, Wuhan, China

Email: *zhangf5y@uregina.ca

How to cite this paper: Zhang, M.L., Zhang, Y.Z., Yang, L., Mei, H.Y., Shen, P.X. and Ge, J.N. (2017) A New Method to Calculate the Recoverable Reserves and Recovery Ratio of Shale Gas Reservoir. Open Journal of Yangtze Gas and Oil, 2, 201-213. https://doi.org/10.4236/ojogas.2017.24016

Received: March 24, 2017

Accepted: October 24, 2017

Published: October 27, 2017

Copyright $\odot 2017$ by authors and Scientific Research Publishing Inc. This work is licensed under the Creative Commons Attribution International License (CC BY 4.0).

http://creativecommons.org/licenses/by/4.0/

(c) (i) Open Access

\begin{abstract}
At present, the most commonly used method to calculate recoverable reserves of shale gas reservoirs is the production decline curve method, which is only applicable to the production wells with decreasing production. For the production wells with constant productions, the material balance method could be used to calculate the recoverable reserves, but it does not consider the particularity of shale gas reservoirs. Under this circumstance, this paper deduces a new calibration method for recoverable reserves of shale gas reservoirs with double porosity medium. The method is based on the material balance equation, which has a wide application range. The method cannot only calculate the recoverable reserves and recoveries of free gas in fractures, but also calculate recoverable reserves and recoveries of free gas and adsorbed gas in the matrix. The calculated results show that the free gas in the shale gas reservoir is mainly in the fractures. The recovery of the free gas in the fractures is relatively high and the recovery of the free gas and adsorbent gas in the matrix is rather low. Gas reservoir recovery and recoverable reserves are more sensitive to abandonment pressure, therefore, in the production process, the reduction of the abandonment pressure of gas reservoir should be attempted. The matrix porosity, the adsorption phase density and the crack compression coefficient have a greater effect on the recovery rate. And the study of these parameters needs to be strengthened in order to obtain more accurate parameters.
\end{abstract}

\section{Keywords}

Recoverable Reserves, Fracture (Matrix), Recovery Ratio, Controlled Reserves, Material Balance

\section{Introduction}

Shale gas reservoir is a kind of unconventional reservoir where the natural gas is 
stored in the dark shale or high-carbon shale and it is a typical in-situ accumulated reservoir [1]. The natural gas is stored in the reservoir formation in the form of free gas and adsorbed gas. Free gas is mainly distributed in the fracture pores and the matrix pores, while the adsorbed gas is mainly distributed on the inner surface of micro-porous matrix system [2]. Chen proposed pressure decline method, material balance method, and production decline method to calculate the conventional gas reservoir recoverable reserves [3]. Chen used the principle of material balance to obtain the recoverable reserves of coalbed gas reservoir with constant volume [4]. However, the methods are not applicable for shale gas reservoirs as status of gas in the coalbed gas reservoirs is different from that of shale gas reservoirs. Ilk proposed an exponential law reduction method that can be used to calculate the recoverable reserves of shale gas reservoirs [5]. Valko proposed an extended exponential reduction method for shale gas reservoirs, which is an empirical method [6]. Duong proposed empirical analysis of the decline in gas production in fractured shale gas reservoirs and calculated recoverable reserves using this method [7]. Duan found that the use of power-law exponential decay methods in the early production of gas wells can predict gas production, recoverable reserves and declining rates [8]. Bai found that shale gas production decline curve can be used to learn most of the hyperbolic decline [9]. Chen introduced the hyperbolic yield reduction model to predict recoverable reserves of shale gas reservoirs [10]. Cao predicted the recoverable reserves of shale gas reservoirs by using a power law exponential diminution model [11].

The widely used recoverable reserves calculation method now is the pressure drop method and the production decline curve method. But the pressure drop method does not consider the particularity of the shale gas reservoir. Thus, the production decline curve method is only applicable to the well with gradually decrease output and it is only an empirical method. Therefore, from the view of mass conservation, this paper establishes the material balance equation of shale gas reservoir, using the equation the controlled reserves, the recoverable reserves and recovery rate could be obtained when the formation pressure reaches the abandonment pressure. Moreover, this paper can calculate the recovery of free gas in the matrix, free gas in the cracks and adsorbed gas in the matrix which does not require the production data and pressure data. It is very convenient for low porosity and low permeability shale gas reservoirs.

\section{Methods}

The development of the shale gas reservoir is an isothermal process, so the shale gas adsorption isotherm [12] is Equation (1).

$$
V_{\mathrm{E}}=\frac{V_{\mathrm{L}} p}{p_{\mathrm{L}}+p}
$$

Adsorption gas is mainly adsorbed on the pore surface of the shale matrix [13], which will cause that the pore size occupied by the gas is smaller than the actual pore size. Ambrose [14] and Cao [15] define the apparent porosity of the 
adsorption phase, which is shown in Equation (2).

$$
\phi_{\mathrm{a}}=4.6545 \times 10^{-5} M \frac{\rho_{\mathrm{h}}}{\rho_{\mathrm{s}}}\left(V_{\mathrm{L}} \frac{p}{p+p_{\mathrm{L}}}\right)
$$

The reserves of free gas in the matrix at the initial formation pressure can be expressed as Equation (3).

$$
G_{\mathrm{mi}}=\frac{V_{\mathrm{m}}\left[\phi_{\mathrm{mi}}\left(1-s_{\mathrm{mwi}}\right)-\phi_{\mathrm{ai}}\right]}{B_{\mathrm{gi}}}
$$

At initial formation pressure, the reserves of free gas in the fracture can be expressed as Equation (4).

$$
G_{\mathrm{fi}}=\frac{V_{\mathrm{fp}}\left(1-s_{\mathrm{fwi}}\right)}{B_{\mathrm{gi}}}
$$

At the initial formation pressure, the reserves of adsorbed gas in the matrix are Equation (5).

$$
G_{\mathrm{ai}}=V_{\mathrm{m}} \rho_{\mathrm{h}} V_{\mathrm{Ei}}
$$

When the formation pressure decreases and desorption of the adsorbed gas takes place, the shale matrix shrinks and deforms which cause the increase of the matrix porosity. When the fluid flows out, the effective stress increases and the rock skeleton volume is compressed, which cause the matrix porosity to decrease. Therefore, the matrix porosity is affected by the effects of both shrinkage of matrix and increase of stress [16].

The relationship between rock deformation and reservoir formation pressure could be explained by the Bangham [17] solid deformation theory and the Langmuir isothermal adsorption model, which is shown in Equation (6).

$$
\Delta \varepsilon=\frac{\rho_{\mathrm{h}} R T V_{\mathrm{L}}}{E V_{0}} \times\left[\ln \left(p_{\mathrm{L}}+p_{\mathrm{i}}\right)-\ln \left(p_{\mathrm{L}}+p\right)\right]
$$

The total deformation of the shale matrix is the sum of the matrix shrinkage and the elastic expansion of the rock, as shown in Equation (7).

$$
\Delta \varepsilon_{\mathrm{z}}=\frac{\rho_{\mathrm{h}} R T V_{\mathrm{L}}}{E V_{0}} \times\left[\ln \left(p_{\mathrm{L}}+p_{\mathrm{i}}\right)-\ln \left(p_{\mathrm{L}}+p\right)\right]-c_{\mathrm{m}}\left(p_{\mathrm{i}}-p\right)
$$

Seidle (1985) [18] proposed an equation to explain the relationship between the matrix porosity and the deformation of the matrix, which is shown in Equation (8).

$$
\frac{\phi_{\mathrm{m}}}{\phi_{\mathrm{mi}}}=1+\left(1+\frac{2}{\phi_{\mathrm{mi}}}\right)\left\{\frac{\rho_{\mathrm{h}} R T V_{\mathrm{L}}}{E V_{0}} \times\left[\ln \left(p_{\mathrm{L}}+p_{\mathrm{i}}\right)-\ln \left(p_{\mathrm{L}}+p\right)\right]-c_{\mathrm{m}}\left(p_{\mathrm{i}}-p\right)\right\}
$$

So the matrix porosity after deformation can be obtained from Equation (9).

$\phi_{\mathrm{m}}=\left\{1+\left(1+\frac{2}{\phi_{\mathrm{mi}}}\right)\left\{\frac{\rho_{\mathrm{h}} R T V_{\mathrm{L}}}{E V_{0}} \times\left[\ln \left(p_{\mathrm{L}}+p_{\mathrm{i}}\right)-\ln \left(p_{\mathrm{L}}+p\right)\right]-c_{\mathrm{m}}\left(p_{\mathrm{i}}-p\right)\right\}\right\} \phi_{\mathrm{mi}}$

As the pressure decreases, the rock particles deform and the initial water ex- 
pands, and the change in the pore volume [19] in the fracture is given by Equation (10).

$$
\Delta V=V_{\mathrm{fp}}\left[\left(c_{\mathrm{f}}+c_{\mathrm{w}} \mathrm{s}_{\mathrm{fwi}}\right)\left(p_{\mathrm{i}}-p\right)\right]
$$

The definition of the coefficient of compressibility can be shown in Equation (11).

$$
\begin{aligned}
C_{\mathrm{mx}} & =-\frac{1}{V_{\mathrm{mp}}} \frac{\Delta V_{\mathrm{mp}}}{\Delta p}=\frac{\phi_{\mathrm{mi}}-\phi_{\mathrm{m}}}{\phi_{\mathrm{mi}}\left(p_{\mathrm{i}}-p\right)} \\
& =\left(1+\frac{2}{\phi_{\mathrm{i}}}\right)\left\{\frac{\rho_{\mathrm{h}} R T V_{\mathrm{L}}}{E V_{0}\left(p_{\mathrm{i}}-p\right)} \times\left[\ln \left(p_{\mathrm{L}}+p\right)-\ln \left(p_{\mathrm{L}}+p_{\mathrm{i}}\right)\right]+c_{\mathrm{m}}\right\}
\end{aligned}
$$

Based on the elastic deformation of matrix rock particles and initial water [20], the material equilibrium equation of formation water is shown in Equation (12).

$$
V_{\mathrm{mp}}\left[1-c_{\mathrm{mx}}\left(p_{\mathrm{i}}-p\right)\right] s_{\mathrm{mw}}=V_{\mathrm{mp}} s_{\mathrm{mwi}}+V_{\mathrm{mp}} c_{\mathrm{w}} s_{\mathrm{mwi}}\left(p_{\mathrm{i}}-p\right)
$$

The irreducible water saturation in the matrix at the present formation pressure is shown in Equation (13).

$$
s_{\mathrm{mw}}=\frac{s_{\mathrm{mwi}}\left[1+c_{\mathrm{w}}\left(p_{\mathrm{i}}-p\right)\right]}{1-c_{\mathrm{mx}}\left(p_{\mathrm{i}}-p\right)}
$$

At the present formation pressure, the residual reserves of adsorbed gas in the matrix is Equation (14).

$$
G_{\mathrm{ar}}=V_{\mathrm{m}} \rho_{\mathrm{h}} V_{\mathrm{E}}
$$

At the present formation pressure, the residual free gas reserves in the matrix can be expressed as Equation (15).

$$
G_{\mathrm{mr}}=\frac{V_{\mathrm{m}}\left[\phi_{\mathrm{m}}\left(1-s_{\mathrm{mw}}\right)-\phi_{\mathrm{a}}\right]}{B_{\mathrm{g}}}
$$

At the present formation pressure, the residual free gas reserves in the fracture type can be shown in Equation (16).

$$
G_{\mathrm{fr}}=\frac{V_{\mathrm{fp}}\left(1-s_{\mathrm{fwi}}\right)-\Delta V}{B_{\mathrm{g}}}
$$

From the conservation of mass, The sum of the original matrix free gas reserves, the original crack free gas reserves, the original matrix adsorbed gas reserves is equal to the sum of the remaining free reserves of the matrix, the remaining free reserves of the fissures, the residual gas reserves of the matrix and the cumulative production.

So the Equation (17) can be obtained when the Equations (3), (4), (5), (10), (14), (15) and (16) are obtained.

$$
\begin{aligned}
G_{\mathrm{p}}= & \frac{V_{\mathrm{fp}}\left(1-s_{\mathrm{fwi}}\right)}{B_{\mathrm{gi}}}+\frac{V_{\mathrm{m}}\left[\phi_{\mathrm{mi}}\left(1-s_{\mathrm{mwi}}\right)-\phi_{\mathrm{ai}}\right]}{B_{\mathrm{gi}}}+V_{\mathrm{m}} \rho_{\mathrm{h}} V_{\mathrm{Ei}}-V_{\mathrm{m}} \rho_{\mathrm{h}} V_{\mathrm{E}} \\
& -\frac{V_{\mathrm{m}}\left[\phi_{\mathrm{m}}\left(1-s_{\mathrm{mw}}\right)-\phi_{\mathrm{a}}\right]}{B_{\mathrm{g}}}-\frac{V_{\mathrm{fp}}\left(1-s_{\mathrm{fwi}}\right)-V_{\mathrm{fp}}\left[\left(c_{\mathrm{f}}+c_{\mathrm{w}} s_{\mathrm{fwi}}\right)\left(p_{\mathrm{i}}-p\right)\right]}{B_{\mathrm{g}}}
\end{aligned}
$$


Then the Equation (18) can be deduced.

$$
\begin{aligned}
G_{\mathrm{p}}= & V_{\mathrm{fp}}\left(\frac{\left(1-s_{\mathrm{fwi}}\right)}{B_{\mathrm{gi}}}-\frac{\left(1-s_{\mathrm{fwi}}\right)}{B_{\mathrm{g}}}+\frac{\left(c_{\mathrm{f}}+c_{\mathrm{w}} s_{\mathrm{fwi}}\right)\left(p_{\mathrm{i}}-p\right)}{B_{\mathrm{g}}}\right) \\
& +V_{\mathrm{m}}\left(\frac{\left[\phi_{\mathrm{mi}}\left(1-s_{\mathrm{mwi}}\right)-\phi_{\mathrm{ai}}\right]}{B_{\mathrm{gi}}}+\rho_{\mathrm{h}} V_{\mathrm{Ei}}-\rho_{\mathrm{h}} V_{\mathrm{E}}-\frac{\left[\phi_{\mathrm{m}}\left(1-s_{\mathrm{mw}}\right)-\phi\right]}{B_{\mathrm{g}}}\right)
\end{aligned}
$$

Substituting Equations (3) and (4) into Equation (18) will deduce Equation (19).

$$
\begin{aligned}
G_{\mathrm{p}}= & \frac{G_{\mathrm{fi}} B_{\mathrm{gi}}}{\left(1-s_{\mathrm{fwi}}\right)}\left(\frac{\left(1-s_{\mathrm{fwi}}\right)}{B_{\mathrm{gi}}}-\frac{\left(1-s_{\mathrm{fwi}}\right)}{B_{\mathrm{g}}}+\frac{\left(c_{\mathrm{f}}+c_{\mathrm{w}} s_{\mathrm{fwi}}\right)\left(p_{\mathrm{i}}-p\right)}{B_{\mathrm{g}}}\right) \\
& +\frac{G_{\mathrm{mi}} B_{\mathrm{gi}}}{\left[\phi_{\mathrm{mi}}\left(1-s_{\mathrm{mwi}}\right)-\phi_{\mathrm{ai}}\right]}\left(\frac{\left[\phi_{\mathrm{mi}}\left(1-s_{\mathrm{mwi}}\right)-\phi_{\mathrm{ai}}\right]}{B_{\mathrm{gi}}}+\rho_{\mathrm{h}} V_{\mathrm{Ei}}-\rho_{\mathrm{h}} V_{\mathrm{E}}-\frac{\left[\phi_{\mathrm{m}}\left(1-s_{\mathrm{mw}}\right)-\phi_{\mathrm{a}}\right]}{B_{\mathrm{g}}}\right)
\end{aligned}
$$

Now some symbols can be defined to simplify the Equation (19).

$$
\begin{gathered}
F=\frac{B_{\mathrm{gi}}}{\left[\phi_{\mathrm{mi}}\left(1-s_{\mathrm{mwi}}\right)-\phi_{\mathrm{ai}}\right]}\left(\frac{\left[\phi_{\mathrm{mi}}\left(1-s_{\mathrm{mwi}}\right)-\phi_{\mathrm{ai}}\right]}{B_{\mathrm{gi}}}+\rho_{\mathrm{h}} V_{\mathrm{Ei}}-\rho_{\mathrm{h}} V_{\mathrm{E}}-\frac{\left[\phi_{\mathrm{m}}\left(1-s_{\mathrm{mw}}\right)-\phi_{\mathrm{a}}\right]}{B_{\mathrm{g}}}\right) \\
Y=G_{\mathrm{p}} \\
M=\frac{B_{\mathrm{gi}}}{\left(1-s_{\mathrm{fwi}}\right)}\left(\frac{\left(1-s_{\mathrm{fwi}}\right)}{B_{\mathrm{gi}}}-\frac{\left(1-s_{\mathrm{fwi}}\right)}{B_{\mathrm{g}}}+\frac{\left(c_{\mathrm{f}}+c_{\mathrm{w}} s_{\mathrm{fwi}}\right)\left(p_{\mathrm{i}}-p\right)}{B_{\mathrm{g}}}\right)
\end{gathered}
$$

Substituting Equation (20) into Equation (19), the Equation (21) can be deduced.

$$
\frac{Y}{M}=G_{\mathrm{fi}}+G_{\mathrm{mi}} \frac{F}{M}
$$

From the above equations, a straight curve could be obtained if the value of $\mathrm{Y} / \mathrm{M}$ is plotted against $\mathrm{F} / \mathrm{M}$ in the Cartesian coordinate system. The intercept of this curve is the free gas reserves in the fracture and the slope of this curve is the free gas reserves in the matrix. The total reserves controlled could be expressed by Equation (22).

$$
G=G_{\mathrm{fi}}+G_{\mathrm{mi}}+\frac{G_{\mathrm{mi}} B_{\mathrm{gi}}}{\left[\phi_{\mathrm{mi}}\left(1-s_{\mathrm{mwi}}\right)-\phi_{\mathrm{ai}}\right]} \rho_{\mathrm{h}} V_{\mathrm{Ei}}
$$

When the formation pressure reaches the abandonment pressure, the well is shut down and the production is stopped. The cumulative production amount at this time is the recoverable reserves of the reservoir. Substituting Equations (3), (4) and (5) into Equation (17) will yield Equation (23).

$$
\begin{aligned}
G_{\mathrm{p}}= & \frac{G_{\mathrm{mi}} B_{\mathrm{gi}}}{\left[\phi_{\mathrm{mi}}\left(1-s_{\mathrm{mwi}}\right)-\phi_{\mathrm{ai}}\right]}\left(\frac{\left[\phi_{\mathrm{mi}}\left(1-s_{\mathrm{mwi}}\right)-\phi_{\mathrm{ai}}\right]}{B_{\mathrm{gi}}}-\frac{\left[\phi_{\mathrm{m}}\left(1-s_{\mathrm{mw}}\right)-\phi_{\mathrm{a}}\right]}{B_{\mathrm{g}}}\right) \\
& +\frac{G_{\mathrm{fi}} B_{\mathrm{gi}}}{\left(1-s_{\mathrm{fwi}}\right)}\left(\frac{\left(1-s_{\mathrm{fwi}}\right)}{B_{\mathrm{gi}}}-\frac{\left(1-s_{\mathrm{fwi}}\right)}{B_{\mathrm{g}}}+\frac{\left(c_{\mathrm{f}}+c_{\mathrm{w}} s_{\mathrm{fwi}}\right)\left(p_{\mathrm{i}}-p\right)}{B_{\mathrm{g}}}\right)+\frac{G_{\mathrm{ai}}}{\rho_{\mathrm{h}} V_{\mathrm{Ei}}}\left(\rho_{\mathrm{h}} V_{\mathrm{Ei}}-\rho_{\mathrm{h}} V_{\mathrm{E}}\right)
\end{aligned}
$$

And because the volume factor of the gas at present formation pressure can 
be expressed by Equation (24).

$$
B_{\mathrm{g}}=\frac{z T p_{\mathrm{sc}}}{z_{\mathrm{sc}} T_{\mathrm{sc}} p}
$$

When the formation pressure reaches the abandonment pressure, substituting Equations (1) and (24) into Equation (23) will yield Equation (25).

$$
\begin{aligned}
G_{\mathrm{R}}= & G_{\mathrm{mi}}\left(1-\frac{\left[\phi_{\mathrm{m}}\left(1-s_{\mathrm{mw}}\right)-\phi_{\mathrm{a}}\right]}{\left[\phi_{\mathrm{mi}}\left(1-s_{\mathrm{mwi}}\right)-\phi_{\mathrm{ai}}\right]} \frac{p_{\mathrm{a}} / \mathrm{z}_{\mathrm{a}}}{p_{\mathrm{i}} / z_{\mathrm{i}}}\right) \\
& +G_{\mathrm{fi}}\left(1-\frac{p_{\mathrm{a}} / z_{\mathrm{a}}}{p_{\mathrm{i}} / z_{\mathrm{i}}}\left(1-\frac{\left(c_{\mathrm{f}}+c_{\mathrm{w}} \mathrm{s}_{\mathrm{fwi}}\right)\left(p_{\mathrm{i}}-p_{\mathrm{a}}\right)}{\left(1-s_{\mathrm{fwi}}\right)}\right)\right)+G_{\mathrm{ai}}\left(\frac{p_{\mathrm{L}}}{p_{\mathrm{i}}} \frac{p_{\mathrm{i}}-p_{\mathrm{a}}}{p_{\mathrm{L}}+p_{\mathrm{a}}}\right)
\end{aligned}
$$

The recovery of free gas in the matrix can be expressed by Equation (26).

$$
E_{\mathrm{Rm}}=1-\frac{\left[\phi_{\mathrm{m}}\left(1-s_{\mathrm{mw}}\right)-\phi_{\mathrm{a}}\right]}{\left[\phi_{\mathrm{mi}}\left(1-s_{\mathrm{mwi}}\right)-\phi_{\mathrm{ai}}\right]} \frac{p_{\mathrm{a}} / z_{\mathrm{a}}}{p_{\mathrm{i}} / z_{\mathrm{i}}}
$$

The recoverable reserves of free gas in the matrix can be expressed by Equation (27).

$$
G_{\mathrm{Rm}}=G_{\mathrm{mi}} E_{\mathrm{Rm}}
$$

The recovery of free gas in the fracture can be expressed by Equation (28).

$$
E_{\mathrm{Rf}}=1-\frac{p_{\mathrm{a}} / \mathrm{z}_{\mathrm{a}}}{p_{\mathrm{i}} / \mathrm{z}_{\mathrm{i}}}\left(1-\frac{\left(c_{\mathrm{f}}+c_{\mathrm{w}} s_{\mathrm{fwi}}\right)\left(p_{\mathrm{i}}-p_{\mathrm{a}}\right)}{\left(1-s_{\mathrm{fwi}}\right)}\right)
$$

The recoverable reserves of free gas in fractures can be expressed by Equation (29).

$$
G_{\mathrm{Rf}}=G_{\mathrm{fi}} E_{\mathrm{Rf}}
$$

The recovery of adsorbed gas in the matrix can be expressed by Equation (30).

$$
E_{\mathrm{Ra}}=\frac{p_{\mathrm{L}}}{p_{\mathrm{i}}} \frac{p_{\mathrm{i}}-p_{\mathrm{a}}}{p_{\mathrm{L}}+p_{\mathrm{a}}}
$$

The recoverable reserves of adsorbed gas in the matrix can be expressed by Equation (31).

$$
G_{\mathrm{Ra}}=G_{\mathrm{ai}} E_{\mathrm{Ra}}
$$

\section{Results}

The basic formation parameters of a certain well of a shale gas reservoir are listed as follows.

$$
\begin{aligned}
& p_{\mathrm{i}}=24.13 \mathrm{MPa}, B_{\mathrm{gi}}=4.82 \times 10^{-3}, \quad S_{\mathrm{mwi}}=0.25, \quad c_{\mathrm{m}}=4.35 \times 10^{-4} \mathrm{MPa}^{-1}, \\
& c_{\mathrm{f}}=2.04 \times 10^{-2} \mathrm{MPa}^{-1}, \quad c_{\mathrm{w}}=4.35 \times 10^{-4} \mathrm{MPa}^{-1}, S_{\mathrm{fwi}}=0, \quad \varphi_{\mathrm{i}}=0.112, \\
& V_{\mathrm{L}}=11.32 \mathrm{~m}^{3} / \mathrm{t}, \quad p_{\mathrm{L}}=2.41 \mathrm{MPa}, \quad \rho_{\mathrm{s}}=0.34 \mathrm{~g} / \mathrm{cm}^{3}, \quad \rho_{\mathrm{h}}=2.65 \mathrm{~g} / \mathrm{cm}^{3}, \\
& E=26800 \mathrm{MPa}, \quad T=366.49 \mathrm{~K}, \quad R=8.134 \times 10^{-6} \mathrm{MPa} /(\mathrm{K} \cdot \mathrm{mol}), \\
& V_{0}=0.0245 \mathrm{~m}^{3} / \mathrm{mol}, \quad M=20 \mathrm{~g} / \mathrm{mol}, \quad p_{\mathrm{a}}=3 \mathrm{MPa}
\end{aligned}
$$


The production data are shown in Table 1.

Table 1. The production data for shale gas reservoir.

\begin{tabular}{ccc}
\hline $\begin{array}{c}G_{\mathrm{p}} \text { (cumulative production) } / \\
10^{8} \mathrm{~m}^{3}\end{array}$ & $\begin{array}{c}P \text { (pressure }) / \\
\mathrm{MPa}\end{array}$ & $\begin{array}{c}B_{\mathrm{g}}(\text { the volume factor of the } \\
\text { gas }) /\left(\mathrm{m}^{3} \cdot \mathrm{m}^{-3}\right)\end{array}$ \\
\hline 0.0000 & 24.13 & 0.0048 \\
1.4357 & 21.37 & 0.0053 \\
3.4847 & 17.24 & 0.0065 \\
5.2855 & 13.79 & 0.0081 \\
6.0276 & 12.41 & 0.0091 \\
6.7830 & 11.03 & 0.0103 \\
6.2137 & 8.45 & 0.0137 \\
9.5728 & 6.34 & 0.0187 \\
10.6503 & 4.83 & 0.0250 \\
11.3299 & 4.01 & 0.0304 \\
\hline
\end{tabular}

Based on the production data in Table 1, the single well reserve, recoverable reserve and recovery could be calculated by using the material balance equation (see Figure 1). The results are shown in Table 2.

Table 2. The results of controlled reserves.

\begin{tabular}{ccccc}
\hline Well & $\begin{array}{c}\text { Free gas reserves in the } \\
\text { matrix } / 10^{8} \mathrm{~m}^{3}\end{array}$ & $\begin{array}{c}\text { Free gas } \\
\text { reserves in } \\
\text { fractures } / 10^{8} \mathrm{~m}^{3}\end{array}$ & $\begin{array}{c}\text { Adsorption gas } \\
\text { reserves } / 10^{8} \mathrm{~m}^{3}\end{array}$ & $\begin{array}{c}\text { Total reserves, } \\
/ 10^{8} \mathrm{~m}^{3}\end{array}$ \\
\hline Well X & 0.7827 & 8.2981 & 11.0225 & 20.1033 \\
\hline Well & $\begin{array}{c}\text { Free gas recovery in } \\
\text { matrix } / \%\end{array}$ & $\begin{array}{c}\text { Free gas recovery } \\
\text { in fractures } / \%\end{array}$ & $\begin{array}{c}\text { Adsorption gas } \\
\text { recovery rate } / \%\end{array}$ & Total recovery $/ \%$ \\
\hline Well X & 56.06 & 93.37 & 39.04 & 62.13 \\
\hline Well & $\begin{array}{c}\text { Free gas recoverable } \\
\text { reserves in matrix, } \\
110^{8} \mathrm{~m}^{3}\end{array}$ & $\begin{array}{c}\text { Free gas } \\
\text { recoverable } \\
\text { reserves in } \\
\text { fractures } / 10^{8} \mathrm{~m}^{3}\end{array}$ & $\begin{array}{c}\text { Adsorbed gas } \\
\text { recoverable } \\
\text { reserves } / 10^{8} \mathrm{~m}^{3}\end{array}$ & $\begin{array}{c}\text { Total recoverable } \\
\text { reserves } / 10^{8} \mathrm{~m}^{3}\end{array}$ \\
\hline Well X & 0.4388 & 7.7478 & 4.3030 & 12.4897 \\
\hline
\end{tabular}

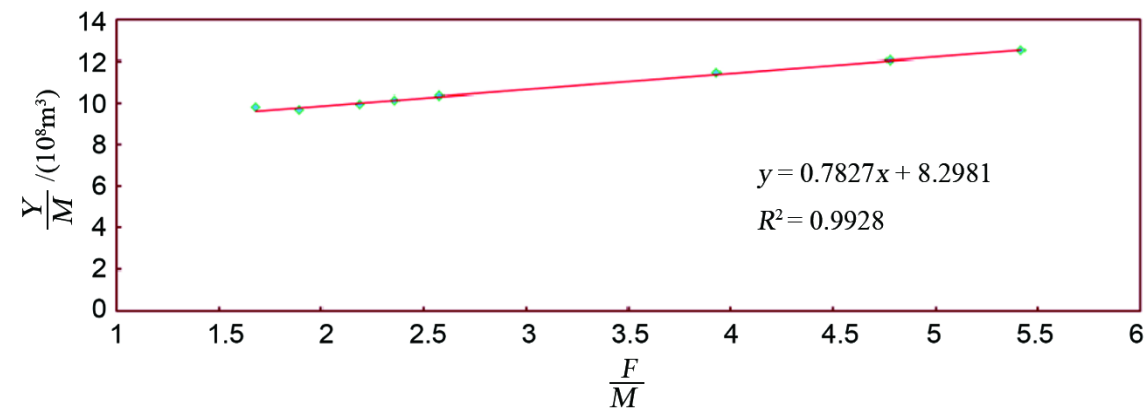

Figure 1. The results for this article using material balance equation. 
Table 2 shows that the free gas mainly exists in the fractures, as the calculated recovery of free gas in the fracture is $93.37 \%$, and the calculated recovery of free gas in the matrix is $56.06 \%$. The calculated recovery of adsorbed gas in the matrix is the lowest, which is $39.04 \%$ and the total recovery of the gas is $62.13 \%$.

Now assuming different abandonment pressures and calculating the recovery and recoverable reserves under different waste pressures, the results are shown in Table 3.

Table 3. The results of recovery for different abandonment pressure calculation.

\begin{tabular}{|c|c|c|c|c|}
\hline $\begin{array}{l}\text { Abandoned } \\
\text { pressure } \\
/ \mathrm{MPa}\end{array}$ & $\begin{array}{l}\text { Free gas } \\
\text { recovery in } \\
\text { matrix } / \%\end{array}$ & $\begin{array}{l}\text { Free gas } \\
\text { recovery in } \\
\text { fractures } / \%\end{array}$ & $\begin{array}{l}\text { Adsorption gas } \\
\text { recovery rate } / \%\end{array}$ & $\begin{array}{l}\text { Recovery } \\
\text { ratio } / \%\end{array}$ \\
\hline 2.8 & 57.43 & 93.87 & 40.92 & 63.42 \\
\hline 2.6 & 58.91 & 94.37 & 42.95 & 64.80 \\
\hline 2.4 & 60.51 & 94.86 & 45.15 & 66.27 \\
\hline 2.2 & 62.24 & 95.33 & 47.54 & 67.84 \\
\hline 2.0 & 64.13 & 95.80 & 50.15 & 69.54 \\
\hline $\begin{array}{l}\text { Abandoned } \\
\text { pressure } \\
/ \mathrm{MPa}\end{array}$ & $\begin{array}{c}\text { Free gas } \\
\text { recoverable } \\
\text { reserves in } \\
\text { matrix } / 10^{8} \mathrm{~m}^{3}\end{array}$ & $\begin{array}{c}\text { Free gas } \\
\text { recoverable } \\
\text { reserves in } \\
\text { fractures } / 10^{8} \mathrm{~m}^{3}\end{array}$ & $\begin{array}{l}\text { Adsorbed gas } \\
\text { recoverable } \\
\text { reserves } / 10^{8} \mathrm{~m}^{3}\end{array}$ & $\begin{array}{c}\text { Total } \\
\text { recoverable } \\
\text { reserves } / 10^{8} \mathrm{~m}^{3}\end{array}$ \\
\hline 2.8 & 0.4495 & 7.7897 & 4.5104 & 12.7496 \\
\hline 2.6 & 0.4611 & 7.8308 & 4.7343 & 13.0262 \\
\hline 2.4 & 0.4736 & 7.8712 & 4.9768 & 13.3216 \\
\hline 2.2 & 0.4872 & 7.9109 & 5.2404 & 13.6384 \\
\hline 2.0 & 0.5020 & 7.9498 & 5.5278 & 13.9796 \\
\hline
\end{tabular}

Table 3 shows the calculation results by applying different abandonment pressure and it could be observed that as the abandonment pressure decreases, both of the recovery of the gas and recoverable reserves increase, and they are sensitive to the abandonment pressure.

Assuming different matrix porosity, then the recovery, controlled reserves and recoverable reserves under different matrix porosity can be calculated. And the results are shown in Table 4.

Table 4. The calculation results of recovery for different matrix porosity.

\begin{tabular}{ccccc}
\hline $\begin{array}{c}\text { Matrix } \\
\text { porosity/f }\end{array}$ & $\begin{array}{c}\text { Free gas } \\
\text { recovery in } \\
\text { matrix/\% }\end{array}$ & $\begin{array}{c}\text { Free gas recovery } \\
\text { in fractures/\% }\end{array}$ & $\begin{array}{c}\text { Adsorption gas } \\
\text { recovery rate/\% }\end{array}$ & $\begin{array}{c}\text { Recovery } \\
\text { ratio/\% }\end{array}$ \\
\hline 0.12 & 68.74 & 93.37 & 39.04 & 62.82 \\
0.14 & 78.49 & 93.37 & 39.04 & 64.43 \\
0.16 & 81.79 & 93.37 & 39.04 & 65.88 \\
0.18 & 83.45 & 93.37 & 39.04 & 67.18 \\
0.20 & 84.45 & 93.37 & 39.04 & 68.35 \\
0.12 & 1.2348 & 8.0026 & 10.5850 & 19.8224 \\
\hline
\end{tabular}




\section{Continued}

\begin{tabular}{ccccc}
\hline $\begin{array}{c}\text { Matrix } \\
\text { porosity/f }\end{array}$ & $\begin{array}{c}\text { Free gas } \\
\text { recovery in } \\
\text { matrix/\% }\end{array}$ & $\begin{array}{c}\text { Free gas recovery } \\
\text { in fractures/\% }\end{array}$ & $\begin{array}{c}\text { Adsorption gas } \\
\text { recovery rate/\% }\end{array}$ & $\begin{array}{c}\text { Recovery } \\
\text { ratio/\% }\end{array}$ \\
\hline 0.14 & 2.2188 & 7.3615 & 9.6147 & 19.1950 \\
0.16 & 3.0333 & 6.8333 & 8.7951 & 18.6617 \\
0.18 & 3.7161 & 6.3924 & 8.0960 & 18.2045 \\
0.12 & 0.8848 & 7.4719 & 4.1322 & 12.4529 \\
0.14 & 1.7415 & 6.8733 & 3.7534 & 12.3682 \\
0.16 & 2.4809 & 6.3801 & 3.4335 & 12.2945 \\
0.18 & 3.1010 & 5.9685 & 3.1606 & 12.2301 \\
0.20 & 3.6270 & 5.6207 & 2.9256 & 12.1733 \\
\hline
\end{tabular}

Table 4 shows that with the increase of matrix porosity, the recovery of free gas in the matrix and the total recovery are increasing, while the recovery of free gas in the cracks and the recovery of adsorbed gas in the matrix are unchanged.

In addition, with the increase of matrix porosity, the controlled reserves of free gas in the matrix are increasing, the recoverable reserves of free gas in the matrix are increasing, the controlled reserves of free gas in the cracks are decreasing, the recoverable reserves of free gas in the cracks are also decreasing, the controlled reserves of the adsorbed gas in the matrix are decreasing, the recoverable reserves of the adsorbed gas in the matrix are decreasing, the total controlled reserves are reduced and the total recoverable reserves are also reduced. Therefore, the porosity of the matrix not only affects free gas recovery in the matrix and total recovery, but also has a great influence on the calculated reserves and recoverable reserves of each part. But there are no effects on the recovery of free gas in the fracture and the recovery of adsorbed gas in the matrix.

Now assuming different density of the adsorption phase and calculating the recovery, controlled reserves and re-coverable reserves under different density of the adsorption phase, the results are shown in Table 5.

Table 5. The calculation results of recovery for different density of the adsorption phase.

\begin{tabular}{ccccc}
\hline $\begin{array}{c}\text { Density of the } \\
\text { adsorption } \\
\text { phase/g.cm }\end{array}$ & $\begin{array}{c}\text { Free gas } \\
\text { recovery in } \\
\text { matrix/\% }\end{array}$ & $\begin{array}{c}\text { Free gas recovery } \\
\text { in fractures/\% }\end{array}$ & $\begin{array}{c}\text { Adsorption gas } \\
\text { recovery rate/\% }\end{array}$ & $\begin{array}{c}\text { Recovery } \\
\text { ratio/\% }\end{array}$ \\
\hline 0.40 & 76.15 & 93.37 & 39.04 & 63.47 \\
0.45 & 80.42 & 93.37 & 39.04 & 64.28 \\
0.50 & 82.54 & 93.37 & 39.04 & 64.88 \\
0.55 & 83.80 & 93.37 & 39.04 & 65.37 \\
0.60 & 84.64 & 93.37 & 39.04 & 65.76 \\
0.40 & 1.6025 & 7.7038 & 10.2583 & 19.5646 \\
0.45 & 2.0602 & 7.3724 & 9.8167 & 19.2492 \\
0.50 & 2.4007 & 7.1279 & 9.4971 & 19.0257 \\
0.55 & 2.6615 & 6.9404 & 9.2446 & 18.8465 \\
0.60 & 2.8681 & 6.7920 & 9.0431 & 18.7032 \\
0.40 & 1.2202 & 7.1929 & 4.0047 & 12.4178 \\
0.45 & 1.6568 & 6.8835 & 3.8323 & 12.3726 \\
0.50 & 1.9815 & 6.6552 & 3.7075 & 12.3443 \\
0.55 & 2.2303 & 6.4801 & 3.6090 & 12.3195 \\
0.60 & 2.4275 & 6.3416 & 3.5303 & 12.2994 \\
\hline
\end{tabular}


Table 5 shows that with the increase of adsorption phase density, the recovery of free gas in the matrix and the total recovery are increasing, while the recovery of free gas in the cracks and the recovery of adsorbed gas in the matrix are unchanged.

In addition, with the increase of adsorption phase density, the controlled reserves of free gas in the matrix are in-creasing, the recoverable reserves of free gas in the matrix are increasing, the controlled reserves of free gas in the cracks are decreasing, the recoverable reserves of free gas in the cracks are also decreasing, the controlled reserves of the adsorbed gas in the matrix are decreasing, the recoverable reserves of the adsorbed gas in the matrix are decreasing, the total controlled reserves are reduced and the total recoverable reserves are also reduced.

Therefore, the density of the adsorption phase not only affects the free gas recovery in the matrix and total recovery, but also has a great influence on the calculated reserves and recoverable reserves of each part. But there are no effects on the recovery of free gas in the fracture and the recovery of adsorbed gas in the matrix.

Now assuming different coefficient of compressibility of the fracture and calculating the recovery, controlled re-serves and recoverable reserves under different coefficient of compressibility of the fracture, the results are shown in Table 6.

Table 6. The calculation results of recovery for different coefficient of compressibility of the fracture.

\begin{tabular}{ccccc}
\hline $\begin{array}{c}\text { Coefficient of } \\
\begin{array}{c}\text { compressibility of the } \\
\text { fracture/ } \mathrm{MPa}^{-1}\end{array}\end{array}$ & $\begin{array}{c}\text { Free gas } \\
\text { recovery in } \\
\text { matrix/\% }\end{array}$ & $\begin{array}{c}\text { Free gas } \\
\text { recovery in } \\
\text { fractures/\% }\end{array}$ & $\begin{array}{c}\text { Adsorption gas } \\
\text { recovery rate/\% }\end{array}$ & $\begin{array}{c}\text { Recovery } \\
\text { ratio/\% }\end{array}$ \\
\hline 0.025 & 56.06 & 94.49 & 39.04 & 59.80 \\
0.035 & 56.06 & 96.96 & 39.04 & 56.32 \\
0.045 & 56.06 & 99.43 & 39.04 & 54.10 \\
0.025 & 0.8936 & 7.6255 & 12.5843 & 21.1034 \\
0.035 & 1.0813 & 6.4807 & 15.2276 & 22.7896 \\
0.045 & 1.2175 & 5.6423 & 17.1457 & 24.0055 \\
0.025 & 0.5010 & 7.2054 & 4.9127 & 12.6192 \\
0.035 & 0.6062 & 6.2836 & 5.9446 & 12.8345 \\
0.045 & 0.6826 & 5.6100 & 6.6934 & 12.9860 \\
\hline
\end{tabular}

Table 6 shows that with the increase of coefficient of compressibility in the fracture, the recovery of free gas in the cracks is increasing, while the recovery of free gas in the cracks and the recovery of adsorbed gas in the matrix are un-changed, the total recovery is decreasing.

In addition, with the increase of coefficient of compressibility in the fracture, the controlled reserves of free gas in the matrix are increasing, the recoverable reserves of free gas in the matrix are increasing, the controlled reserves of free 
gas in the cracks are decreasing, the recoverable reserves of free gas in the cracks are also decreasing, the controlled reserves of the adsorbed gas in the matrix are increasing, the recoverable reserves of the adsorbed gas in the matrix are increasing, the total controlled reserves are increasing and the total recoverable reserves are also increasing.

Therefore, the coefficient of compressibility in the fracture not only affects the free gas recovery in the cracks and total recovery, but also has a great influence on the calculated reserves and recoverable reserves of each part. But there are no effects on the recovery of free gas in the matrix and the recovery of adsorbed gas in the matrix.

\section{Conclusions}

In this paper, a calibration method of controlled reserves, recoverable reserves and recovery of shale gas reservoirs is established, which is widely applicable. It is shown from a realistic example that this method is simple and practically applicable. The calculated results show that the free gas in the shale gas reservoir mainly exists in the fracture and the proportion of the free gas in the matrix is small. But the adsorbed gas occupies most of the reserves. The recovery of adsorbed gas in the matrix is low, so in the later development, the matrix adsorption gas has great potential.

It also reveals that the recoverable reserves and recoveries are very sensitive to the abandonment pressure. Therefore, during the development process, the gas flow resistance should be minimized and the abandonment pressure should be reduced to obtain higher recovery and recoverable reserves. Besides, the porosity in matrix and the adsorption phase density affect the recovery of free gas in the matrix, and the fracture compression coefficient affects the recovery of free gas in the fracture. These three parameters have a significant effect on the calculation of reserves and recoverable reserves. Therefore, it is necessary to strengthen the study of these three parameters in future work in order to obtain more accurate values for the calculation of reserves.

\section{References}

[1] Zhang, J., Jin, Z. and Yuan, M. (2004) Reservoiring Mechanism of Shale Gas and Its Distribution. Natural Gas Industry, 24, 15-18.

[2] Hay, D. (2012) Unconventional Hydrocarbon Resources in China and the Prospect of Exploration and Development. Petroleum Exploration and Development, 39, 139-146. https://doi.org/10.1016/S1876-3804(12)60026-3

[3] Chen, Y. (2000) Calculation Methods of Recoverable Reserves of Oilfields. Xinjiang Petroleum Geology, 5, 15-24.

[4] Chen, Y. and Hu, J. (2008) Derivation of Methods for Estimating OGIP and Recoverable Reserves and Recovery Ratio of Saturated Coal-Seam Gas Reservoirs. Oil \& Gas Geology, 29, 151-156.

[5] Ilk, D., Rushing, J. A., Perego, A.D., et al. (2008) Exponential vs. Hyperbolic Decline in Tight Gas Sands: Understanding the Origin and Implications for Reserve Esti- 
mates Using Arps' Decline Curves. Society of Petroleum Engineers, Dallas.

[6] Valkó, P.P. (2009) Assigning Value to Stimulation in the Barnett Shale: A Simultaneous Analysis of 7000 Plus Production Hystories and Well Completion Records. Society of Petroleum Engineers, Dallas.

[7] Duong, A.N. (2010) An Unconventional Rate Decline Approach for Tight and Fracture-Dominated Gas Wells. Society of Petroleum Engineers, Dallas. https://doi.org/10.2118/137748-MS

[8] Duan, Y.G., Cao, T.K., Wang, R. and Wei, M.Q. (2013) Analysis of Power Factor Index of Shale Gas Production. Journal of Southwest Petroleum University (Natural Science Edition), 35, 172-176.

[9] Bai, Y.H., Yang, H. and Chen, G.H. (2013) Method for Determining Key Parameters in Typical Curve of Shale Gas Production. Special Oil and Gas Reservoirs, 20, 65-68.

[10] Chen, Y.Q., Li, J., Qi, Y.D. and Zhang, X. (2014) Determination Methods of Geological Resources, Recoverable Resources and Well Controlled Recoverable Reserves in Shale Gas Reservoir. Xin Jiang Petroleum Geology, 35, 547-551.

[11] Cao, A., Cao, G.J. and Zhang, X. (2015) Prediction of Recoverable Reserves in Unconventional Gas Reservoirs by the Power-Law Loss Ratio Rate Decline Relation. Liaoning Chemical Industry, 44, 315-317.

[12] Fu, X.C., Shen, W.X. and Yao, T.Y. (2006) Physical Chemistry. Higher Education Press, Beijing, 360-375.

[13] Xiong, Y., Xiong, W.L. and Liu, Q.G. (2015) Calculation of Shale Gas Reserves Based on the Volume of Adsorbed Gas. Geological Science and Technology Information, 34, 139-143.

[14] Ambrose, R.J., Hartman, R.C., Diaz Campos, M., Akkutlu, I.Y. and Sondergeld, C. (2010) New Pore-Scale Considerations for Shale Gas in Place Calculations. In SPE Unconventional Gas Conference. Society of Petroleum Engineers, Dallas. https://doi.org/10.2118/131772-MS

[15] Cao, T., Duan, Y., Wang, R., Fang, Q. and Wei, M. (2011) Evaluation of Shale Gas Reserves Considering Multi-Component Adsorption. Reservoir Evaluation \& Development, 1, 68-70.

[16] Liu, B., Yin, H., Wang, X. and Li, Q. (2013) Material Balance Equation with Revised Rock Compressibility for Shale Gas Reserve Calculation. Oil \& Gas Geology, 34, 471-474.

[17] Tan, M.H. and Huang, Y.Y. (1985) Superficial Physical Chemistry. China Building Industry Press, Beijing, 50-54.

[18] Seidle, J.R. and Huitt, L.G. (1995) Experimental Measurement of Coal Matrix Shrinkage Due to Gas Desorption and Implications for Cleat Permeability Increases. In International Meeting on Petroleum Engineering. Society of Petroleum Engineers, Dallas. https://doi.org/10.2118/30010-MS

[19] Zhang, L., Chen, G., Zhao, Y., Liu, Q. and Zhang, H. (2013) A Modified Material Balance Equation for Shale Gas Reservoir and a Calculation Method of Shale Gas Reserves. Gas Industry, 33, 66-70.

[20] King, G.R. (1993) Material-Balance Techniques for Coal-Seam and Devonian Shale Gas Reservoirs with Limited Water Influx. SPE Reservoir Engineering, 8, 67-72. https://doi.org/10.2118/20730-PA 


\section{Nomenclature}

$p$ is the reservoir formation pressure, MPa;

$p_{\mathrm{i}}$ is the reservoir initial formation pressure, $\mathrm{MPa}$;

$V_{\mathrm{E}}$ is the adsorption amount under the reservoir formation pressure, $\mathrm{m}^{3} / \mathrm{t}$;

$V_{\mathrm{L}}$ is the langmuir volume, $\mathrm{m}^{3} / \mathrm{t}$;

$p_{\mathrm{L}}$ is the langmuir pressure, $\mathrm{MPa}$;

$\phi_{\mathrm{a}}$ is the porosity of adsorption phase, $\mathrm{f}$;

$M$ is the molar weight, $\mathrm{g} / \mathrm{mol}$;

$\rho_{\mathrm{h}}$ is the density of the rock, $\mathrm{g} / \mathrm{cm}^{3}$;

$\rho_{\mathrm{s}}$ is the density of the adsorption phase, $\mathrm{g} / \mathrm{cm}^{3}$;

$B_{\mathrm{gi}}$ is the volume factor of the gas at the initial formation pressure, $\mathrm{m}^{3} / \mathrm{m}^{3}$;

$s_{\mathrm{mwi}}$ is the initial water saturation of the matrix at the initial formation pressure, $\mathrm{f}$;

$\phi_{\mathrm{mi}}$ is the matrix porosity at the initial formation pressure, f;

$\phi_{\mathrm{ai}}$ is the porosity of adsorption phase at the initial formation pressure, $\mathrm{f}$;

$G_{\mathrm{mi}}$ is the reserves of the free gas in the matrix at the initial formation pressure, $10^{8} \mathrm{~m}^{3}$;

$V_{\mathrm{m}}$ is the total volume of the matrix, $10^{8} \mathrm{~m}^{3}$;

$S_{\mathrm{fwi}}$ is the initial water saturation in the fracture, $\mathrm{f}$;

$G_{\mathrm{fi}}$ is the reserves of free gas in the fracture at initial pressure, $10^{8} \mathrm{~m}^{3}$;

$V_{\mathrm{fp}}$ is the fracture pore volume, $10^{8} \mathrm{~m}^{3}$;

$G_{\mathrm{ai}}$ is the reserves of adsorbed gas at the initial formation pressure, $10^{8} \mathrm{~m}^{3}$;

$V_{\mathrm{Ei}}$ is the adsorption amount at the initial formation pressure, $\mathrm{m}^{3} / \mathrm{t}$;

$\Delta \varepsilon$ is the deformation of the rock caused by the desorption of gas, dimensionless;

$R$ is the gas constant, $\mathrm{MPa} /(\mathrm{K} \cdot \mathrm{mol})$;

$T$ is the temperature of the reservoir formation, $\mathrm{K}$;

$V_{0}$ is the molar based specific volume, $\mathrm{m}^{3} / \mathrm{mol}$;

$E$ is the Young's modulus, $\mathrm{MPa}$;

$\Delta \varepsilon_{z}$ is the elastic expansion of the rock under effective stress and matrix shrinkage, dimensionless;

$c_{\mathrm{m}}$ is the elastic coefficient of compressibility for the rock, $\mathrm{MPa}^{-1}$;

$\phi_{\mathrm{m}}$ is the matrix porosity after deformation;

$\Delta V$ is the change of the pore volume in the fracture, $10^{8} \mathrm{~m}^{3}$;

$c_{\mathrm{f}}$ is the coefficient of compressibility of the fracture, $\mathrm{MPa}^{-1}$;

$C_{\mathrm{w}}$ is the coefficient of compressibility of the irreducible water, $\mathrm{MPa}^{-1}$;

$V_{\mathrm{mp}}$ is the Matrix pore volume, $10^{8} \mathrm{~m}^{3}$;

$S_{\mathrm{mw}}$ is the saturation of bound water under pressure, $\mathrm{f}$;

$G_{\mathrm{ar}}$ is the remaining reserves of adsorbed gas in the matrix at present formation pressure, $10^{8} \mathrm{~m}^{3}$;

$G_{\mathrm{fr}}$ is the remaining reserves of free gas in the fracture under present formation pressure, $10^{8} \mathrm{~m}^{3}$;

$G_{\mathrm{R}}$ is the recoverable reserves at abandoned pressure, $10^{8} \mathrm{~m}^{3}$;

$B_{\mathrm{g}}$ is the volume factor of the gas at present formation pressure, $\mathrm{m}^{3} / \mathrm{m}^{3}$;

$p_{\mathrm{a}}$ is the abandoned pressure, $\mathrm{MPa}$;

$E_{\mathrm{Rm}}$ is the. recovery of free gas in matrix, $\mathrm{f}$;

$G_{\mathrm{Rm}}$ is the recoverable reserves of free gas in the matrix, $10^{8} \mathrm{~m}^{3}$;

$E_{\mathrm{Rf}}$ is the recovery of free gas in fractures, $\mathrm{f}$;

$G_{\mathrm{Rf}}$ is the recoverable reserves of free gas in fractures, $10^{8} \mathrm{~m}^{3}$;

$G_{\mathrm{Ra}}$ is the recoverable gas in the matrix, $108 \mathrm{~m}^{3}$. 